DOI: 10.12731/2658-6649-2019-11-5-94-100

УДК 616.1

\title{
ДИАГНОСТИКА МЕТАБОЛИЧЕСКОГО СИНДРОМА НА СОВРЕМЕННОМ ЭТАПЕ
}

Москаленко О.Л., Смирнова О.В., Каспаров Э.В., Зайцева О.И.

Метаболический синдром (МС) является серьезной медицинской, соичиальной и экономической проблемой. Своевременная диагностика МС, терапия (лечение ожирения, нарушений углеводного обмена, артериальной гипертензии, дислипидемии) и профилактика (контроль массы тела, определение индекса массы тела, физическая активность и рациональное питание) будут способствовать эффективному снижению риска сердечно-сосудистых осложнений, связанных с атеросклерозом.

Ключевые слова: метаболический синдром; ожирение; избыточный вес; осложнения; индекс массы тела.

\section{DIAGNOSTIC CRITERIA OF METABOLIC SYNDROME}

\section{Moskalenko O.L., Smirnova O.V., Kasparov E.V., Zaitseva O.I.}

Metabolic syndrome (MS) is a serious medical, social and economic problem. Timely diagnosis of MS, therapy (treatment of obesity, carbohydrate metabolism disorders, arterial hypertension, dyslipidemia) and prevention (control of body weight, determination of body mass index, physical activity and balanced diet) will effectively reduce the risk of cardiovascular complications associated with atherosclerosis.

Keywords: metabolic syndrome; obesity; overweight; complications; body mass index.

За последние несколько лет в России отмечается увеличение числа пациентов с метаболическим синдромом (МС). МС является актуальной проблемой современной медицины. Термин МС - это увеличение массы висцерального жира, снижением чувствительности периферических тканей к инсулину, которые нарушают все виды обменов, и вызывают артериальную гипертензию. Длительный период может протекать бессимптомно. 
Целью нашего исследования явилось изучение МС, как фактора риска развития сердечно-сосудистых заболеваний.

\section{Материал и методы}

Представлен обзор исследований, которые посвящены МС с использованием поисковых систем научных публикаций в библиографических и peферативных базах данных Scopus, PubMed, MEDLINE, РИНЦ, Google Scholar с проведением анализа литературных данных. Обсуждаются современные подходы в диагностике МС, т.к. является серьезной медицинской, социальной и экономической проблемой.

\section{Результаты}

Специалисты ВО3 описали МС в качестве «пандемии 21 века». На сегодняшний день имеются данные о 20-ти эпидемиологических исследованиях, которые доказывают, что МС является распространенным заболеванием в России и мире. Согласно литературным данным: «МС чаще встречается среди пациентов старшего и среднего возраста от $20,0 \%$ до $40,0 \% »[1]$.

Основными компонентами МС являются: инсулинорезистентность с относительной гиперинсулинемией, нарушение толерантности к глюкозе, абдоминальное (висцеральное) ожирение, артериальная гипертония, атерогенная дислипидемия. Критерии МС периодически пересматриваются. Экспертные комиссии: «ВОЗ (1998 г.), National Cholesterol Education Program Adult Treatment Panel III (2001-2004 гг.), International Diabetes Federation (2005 г.) и Всероссийского научного общества кардиологов (2009 г.)» используют различные варианты критериев. Различные ученые дифференцированно подходят к определению главного фактора МС и комбинаций его компонентов.

В России были проведены единичные эпидемиологические исследования в нескольких регионах, которые посвящены распространенности МС и отсутствием прогностических данных, и выделения разных клинических вариантов МС. Впрочем, с практической точки зрения, выделение больных с разными вариантами МС значимо, т.к. в зависимости от комбинации компонентов МС будет различной тактика ведения таких больных. Также важно наличие этнических и региональных особенностей развития МС, что обусловлено как генетической гетерогенностью различных популяций, так и особенностями образа жизни, включая национальные особенности питания [1]. 
Интерес врачей разных специальностей, таких как, эндокринологи, кардиологи, врачи общей практики определен высоким риском развития сердечно-сосудистых заболеваний при выявлении у пациента комплекса компонентов, объединенных в МС по сравнению с риском, обусловленным отдельными его компонентами [2].

Важным моментом считается еще обратимость МС в целом, так и его отдельных факторов. Выводы множества исследований говорят, о влиянии на один из компонентов МС, возможно, достичь видимого улучшения общего состояния за счет компенсации изменений в других звеньях его патогенеза [6].

Нарушение углеводного обмена, абдоминальное ожирение, дислипидемия, гипертензия, развитие сахарного диабета 2 типа и сердечно-сосудистых заболеваний подтверждает наличие МС [4].

В настоящее время в России диагностика МС основана на данных осмотра, анамнезе, результатах лабораторных и инструментальных исследований. Основной критерий диагностики МС: центральное (абдоминальное) ожирение, при котором объем талии у женщин $<80,0$ см и у мужчин $<94,0$ см. Дополнительный критерий: артериальная гипертензия - АД $\geq 140 / 90$ мм.рт.ст.; увеличение содержания триглицеридов $\geq 1,7$ ммоль/л и холестерина ЛНП > 3,0 ммоль/л; уменьшение концентрации холестерина ЛВП $<1,0$ ммоль/л у мужчин; $<1,2$ ммоль/л у женщин; гипергликемия натощак - глюкоза в плазме крови натощак $\geq 6,1$ ммоль/л: нарушенная толерантность к глюкозе - глюкоза в плазме крови через 2 ч. после глюкозотолерантного теста (ГТТ) в пределах $\geq 7,8$ и $\leq 11,1$ ммоль/л. Наличие 3 -х критериев позволяет устанавливать диагноз МC [4].

\section{Выводы}

Таким образом, МС является серьезной медицинской, социальной и экономической проблемой. Своевременная диагностика МС, терапия (лечение ожирения, нарушений углеводного обмена, артериальной гипертензии, дислипидемии) и профилактика (контроль массы тела и определение индекса массы тела, физическая активность и рациональное питание) будут способствовать эффективному снижению риска сердечно-сосудистых осложнений, связанных с атеросклерозом (инфаркт и инсульт).

Информация о конфликте интересов. Авторы заявляют об отсутствии конфликтов интересов.

Информация о спонсорстве. Исследование не имело спонсорской поддержки. 


\section{Сиисок литературы}

1. Мамедов М.Н. Метаболический синдром в России. Распространенность, клинические особенности и лечение. М.Н. Мамедов, Р.Г. Оганов М.: ФГУП Издательство «Известия» Управления делами Президента Российской Федерации. 2011. 160 с.

2. Ожирение, как фактор риска сердечно-сосудистых заболеваний и патологических состояний, обусловленных избыточным весом. Москаленко О.Л., Смирнова О.В., Каспаров Э.В. и др. В сборнике: Сложные системы в экстремальных условиях Материалы XIX Всероссийского симпозиума с международным участием. Федеральное государственное бюджетное научное учреждение «Федеральный исследовательский центр «Красноярский научный центр Сибирского отделения Российской академии наук». 2018. C. 147-149.

3. Особенности полиморфизма генов PNPLA 3 (RS738409), TM6SF 2 (RS58542926), MBOA T7 (RS641738), как способ диагностики иммунопатологии при жировом гепатозе. Москаленко О.Л., Смирнова О.В., Каспаров Э.В. и др. Российский аллергологический журнал. 2018. Т. 15. № 1-2. С. 64-67.

4. Рекомендации по ведению больных с метаболическим синдромом (клинические рекомендации), Москва. 2013. 42 с.

5. Связь числа компонентов метаболического синдрома с распространенностью и выраженностью поражения органов-мишеней / Ю.В. Жернакова, И.Е. Чазова, В.Б. Мычка и др. // Системные гипертензии. 2011. Т. 8. №2. С. 50-54.

6. Grundy S.M. Obesity, metabolic syndrome, and cardiovascular disease // J.Clin. Endocrinol. Metab. 2004. V. 89, pp. 2595-2600.

7. Marchesini G., Forlani G., Cerrelli F. et al. WHO and ATP III proposals for the definition of the metabolic syndrome in patients with type 2 diabetes // Diabetic Medicine 2004. V.21, pp. 383-387.

\section{References}

1. Mamedov M.N., Oganov R.G. Metabolicheskij sindrom v Rossii. Rasprostranennost', klinicheskie osobennosti i lechenie [Metabolic syndrome in Russia. Prevalence, clinical features and treatment]. M.: FGUP Izdatel'stvo «Izvestiya» Upravleniya delami Prezidenta Rossijskoj Federacii. 2011. $160 \mathrm{s.}$

2. Moskalenko O.L., Smirnova O.V., Kasparov E.V. i dr. Ozhirenie, kak faktor riska serdechno-sosudistyh zabolevanij i patologicheskih sostoyanij, obuslovlennyh izbytochnym vesom [Obesity as a risk factor for cardiovascular diseases and pathological conditions caused by overweight]. V sbornike: Slozhnye sistemy v ekstremal'nyh usloviyah Materialy XIX Vserossijskogo simpoziu- 
ma s mezhdunarodnym uchastiem. Federal'noe gosudarstvennoe byudzhetnoe nauchnoe uchrezhdenie «Federal'nyj issledovatel'skij centr «Krasnoyarskij nauchnyj centr Sibirskogo otdeleniya Rossijskoj akademii nauk». 2018. S. $147-149$.

3. Moskalenko O.L., Smirnova O.V., Kasparov E.V. i dr. Osobennosti polimorfizma genov PNPLA 3 (RS738409), TM6SF 2 (RS58542926), MBOA T7 (RS641738), kak sposob diagnostiki immunopatologii pri zhirovom gepatoze [Features of the polymorphism of the PNPLA 3 genes (RS738409), TM6SF 2 (RS58542926), MBOA T7 (RS641738), as a way to diagnose immunopathology in fatty hepatosis]. Rossijskij allergologicheskij zhurnal [Russian allergological journal]. 2018. T. 15. № 1-2. S. 64-67.

4. Rekomendacii po vedeniyu bol'nyh s metabolicheskim sindromom (klinicheskie rekomendacii). [Recommendations for the management of patients with metabolic syndrome (clinical guidelines]. Moskva. 2013. $42 \mathrm{~s}$.

5. Zhernakova Yu.V., CHazova I.E., Mychka V.B. i dr. Svyaz' chisla komponentov metabolicheskogo sindroma s rasprostranennost'yu i vyrazhennost'yu porazheniya organov-mishenej [Relationship of the number of components of metabolic syndrome with the prevalence and severity of target organ damage]. Sistemnye gipertenzii [Systemic hypertension]. 2011. T. 8. №2. S. 50-54.

6. Grundy S.M. Obesity, metabolic syndrome, and cardiovascular disease. J.Clin. Endocrinol. Metab. 2004. V. 89, pp. 2595-2600.

7. Marchesini G., Forlani G., Cerrelli F. et al. WHO and ATP III proposals for the definition of the metabolic syndrome in patients with type 2 diabetes. Diabetic Medicine 2004. V.21, pp. 383-387.

\section{ДАННЫЕ ОБ АВТОРАХ}

Москаленко Ольга Леонидовна, старший научный сотрудник, кандидат биологических наук

Федеральное государственное бюджетное научное учреждение «Научно-исследовательский институт медииинских проблем Севера»

ул. Партизана Железняка, 32, г. Красноярск, 660022, Российская Федераиия

gre-ll@mail.ru

ORCID: 0000-0003-4268-6568

Смирнова Ольга Валентиновна, д.м.н., профессор, заведующая лабораторией клинической патофизиологии 
Федеральное государственное бюджетное научное учреждение «Федеральный исследовательский иентр «Красноярский научный иентр Сибирского отделения Российской академии наук» "Научно-исследовательский институт медицинских проблем Севера» ул. Партизана Железняка, 32, г. Красноярск, 660022, Российская Федераиия ovsmirnova71@mail.ru

Каспаров Эдуард Вильямович, д.м.н., профессор, директор НИИ МПС ФИЦ КНЦ СО РАН, зам. директора

Научно-исследовательский институт медииинских проблем Севера, Федеральное государственное бюджетное научное учреждение «Федеральный исследовательский центр «Красноярский научный иентр Сибирского отделения Российской академии наук» ул. Партизана Железняка, 32, г. Красноярск, 660022, Российская Федерация impn@impn.ru

Зайцева Ольга Исаевна, д.м.н., профессор, главный научный сотрудник лаборатории клинической патофизиологии Научно-исследовательский институт медииинских проблем Севера, Федеральное государственное бюджетное научное учреждение «Федеральный исследовательский иентр «Красноярский научный иентр Сибирского отделения Российской академии наук» ул. Партизана Железняка, 32, г. Красноярск, 660022, Российская Федераиия impn@impn.ru

\section{DATA ABOUT THE AUTHORS}

Moskalenko Olga Leonidovna Senior Researcher, Candidate of Biological Sciences

Federal State Budgetary Scientific Institution «Scientific Research Institute of medical problems of the North»

3g, Partizan Zheleznyaka str., Krasnoyarsk, 660022, Russian Federation gre-ll@mail.ru

ORCID: 0000-0003-4268-6568

Smirnova Olga Valentinovna, MD, Professor, Head of the Laboratory of Clinical Pathophysiology 
Scientific Research Institute of Medical Problems of the North 3g, Partizan Zheleznyaka Str., Krasnoyarsk, 660022, Russian Federation ovsmirnova71@mail.ru

Kasparov Eduard Vilyamovich, MD, Professor, Director

Scientific Research Institute of medical problems of the North, Federal Research Center «Krasnoyarsk Science Center» of the Siberian Branch of the Russian Academy of Sciences, Krasnoyarsk, Krasnoyarsk territory (krai), Russia

3d, Partizan Zheleznyaka Str., Krasnoyarsk, 660022, Russian Federation impn@impn.ru

Zaitseva Olga Isaevna, MD, professor, chief researcher of the laboratory of clinical pathophysiology Scientific Research Institute of Medical Problems of the North 3g, Partizan Zheleznyaka Str., Krasnoyarsk, 660022, Russian Federation impn@impn.ru 